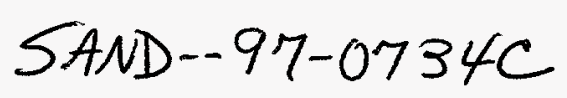

* SAMPLE (Sandia Agile MEMS Prototyping, Layout tools, and Education)

\author{
^Brady R. Davies, Carole Craig Barron, Jeffry J. Sniegowski, and M. Steven Rodgers \\ Intelligent Micromachine Department \\ Sandia National Laboratories, P.O. Box 5800 MS 1080 \\ Albuquerque, New Mexico 87185-1080 \\ http://www.mdl.sandia.gov/Micromachine \\ CONF- $970968--3$
}

\begin{abstract}
The SAMPLE (Sandia Agile MEMS Prototyping, Layout tools, and Education) service makes Sandia's state-of-the-art surface-micromachining fabrication process, known as SUMMiT, available to US industry for the first time. The service provides a short course and customized computer-aided design (CAD) tools to assist customers in designing micromachine prototypes to be fabricated in SUMMiT. Frequent small-scale manufacturing runs then provide SAMPLE designers with hundreds of sophisticated MEMS (MicroElectroMechanical Systems) chips. SUMMiT (Sandia Ultra-planar, Multi-level MEMS Technology) offers unique surface-micromachining capabilities, including four levels of polycrystalline silicon (including the ground layer), flanged hubs, substrate contacts, one-micron design rules, and chemical-mechanical polishing (CMP) planarization. This paper describes the SUMMiT process, design tools, and other information relevant to the SAMPLE service and SUMMiT process.
\end{abstract}

\title{
2.0 INTRODUCTION
}

MicroElectroMechanical Systems (MEMS) technology has tremendous promise and has generated a significant amount of interest in the academic, lab, government, and business sectors. This interest is primarily focused on the perceived potential performance and cost advantages associated with microscale devices fabricated using conventional silicon processing technology and equipment. While the market for micromachined devices is expected to reach between $\$ 10^{1}$ billion to $\$ 14^{2}$ billion dollars per year by the year 2000, the current and projected market is very segmented. Efficiently and profitably accessing the segmented MEMS markets will likely require significant design flexibility, integration between micromachines and microelectronics, well characterized processes, and a full suite of design, simulation, and analysis tools. In order to be profitable, fixed costs associated with developing and maintaining repeatable fabrication processes (equipment, facility, and other process development costs), and the fixed costs associated with designing, analyzing, and laying out micromachines and microelectronics (device development costs), must be shared by several or perhaps many different MEMS products. By amortizing the costs of developing multiple market segments or niches, the per-chip costs can be effectively minimized allowing the MEMS technology to pervade a broad scope of market segments and applications.

Process development and MEMS device fabrication is accomplished in Sandia's Microelectronics Development Laboratory (MDL). The MDL, shown in Figure 1, is a 30,000 square foot, class 1 semiconductor fabrication facility located in Albuquerque, NM. The MDL is a modern, well-equipped CMOS fabrication facility with both $2 \mu \mathrm{m}$ and $0.5 \mu \mathrm{m}$ CMOS technologies. The facility has been adapted to enable the advancement of other technologies, such as micromechanics, in addition to the continued development of sub-micron CMOS. Micromechanics benefits from the wide variety of equipment and processes in existence to support the baseline CMOS, but are constrained by CMOS compatibility issues ${ }^{3}$.

\footnotetext{
* This work was supported by the United States Department of Energy under Contract DE-AC04-94AL85000. Sandia is a multiprogram laboratory operated by Sandia Corporation, a Lockheed Martin Company, for the United States Department of Energy.

${ }^{\wedge}$ B.R.D. (correspondence): Email: brdavie@sandia.gov; Telephone: (505) 844-5600

C.C.B. (correspondence): Email: ccbarron@sandia.gov; Telephone: (505) 844-6583

J.J.S. (correspondence): Email: sniegojj@sandia.gov; Telephone: (505) 844-2718

M.S.R. (correspondence): Email: rodgersm@sandia.gov; Telephone: (505) 844-1784

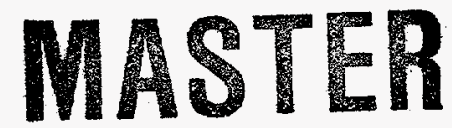




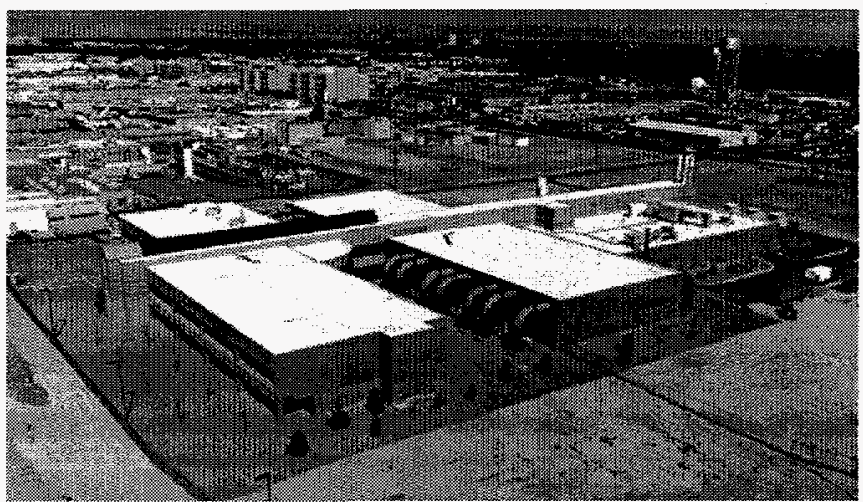

Figure 1. The Microelectronics Development Laboratory at Sandia National Laboratories

Various fabrication challenges including layer topography, inter-layer stiction, and residual stress deformation, to name but a few, were resolved to facilitate reliable fabrication of MEMS devices in the MDL. The resulting MEMS fabrication processes are being made available to virtually any MEMS designer for prototyping micromachines. A description of the process, design tools, design issues, and example devices follows.

\subsection{SANDIA ULTRA-PLANER MULTI-LEVEL MEMS TECHNOLOGY (SUMMIT) PROCESS}

Sandia National Laboratories has made available the SAMPLE (Sandia Agile MEMS Prototyping, Layout tools, and Education) program in part to allow MEMS developers to develop devices using a very flexible (from a micromachining design perspective) MEMS process. The MEMS fabrication process, developed by researchers at Sandia, (called Sandia Ultra-Planar Multi-Level MEMS Technology or SUMMiT for short) is flexible, even though the process steps, material properties, and structural layer spacing are fixed, because the designer has greater latitude to control lateral geometry and greater flexibility to use multiple structural layers than is available in any other process currently available.

\subsection{Four-Level Polycrystalline Micromachining Process}

Initially, the four-level polycrystalline silicon process was developed to facilitate the fabrication of useful micromechanical actuators. In general, micromechanical actuators have not experienced the depth and breadth of development and applications that micromechanical sensors have experienced. Deficiencies in torque and coupling of actuators to other structures were identified as the primary obstacles inhibiting the widespread application of micromechanical actuators. The four-level poly process was developed at Sandia to enable fabrication of actuators that were capable of sufficient torque and coupling flexibility to make micromechanical actuators practical ${ }^{4,5}$. The process also enables the development of devices with signficantly greater levels of functionality and flexibility than other comparable processes can provide.

This four-level process includes three movable levels of polysilicon in addition to a stationary level for a total of four levels of polysilicon. These levels are each separated by sacrificial oxide layers. A total of eight mask levels are used in this process. An additional friction-reducing layer of silicon nitride is placed between the layers that form bearing surfaces. The inset (lower right) to Figure 2 illustrates a bearing formed between two layers of mechanical poly. Figure 2 shows two combdrive actuators driving a set of linkages to a set of rotary gears. This engine can be rotated by applying sinusoidal driving forces $90^{\circ}$ out of phase with each other to each of the comb-drive actuators. Operation of the small gears (shown in the inset) at rotational speeds in excess of 300,000 revolutions per minute has been demonstrated. The operational lifetime of these small devices exceed $8 \times 10^{8}$ revolutions. This smaller gear is shown driving a larger $(1.6 \mathrm{~mm}$ diameter) gear. This larger gear has been driven as fast as $4800 \mathrm{rpm}^{3}$. 
Figure 2. Orthogonal acting comb-drive actuators

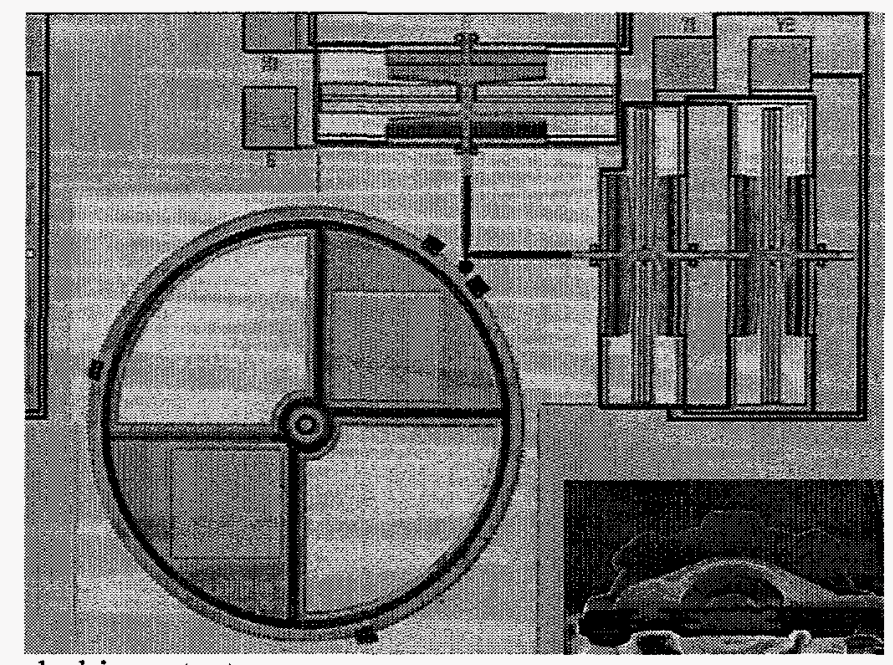

To increase the torque available from a rotary drive, a multi-level microtransmission has been developed. ${ }^{6}$ This transmission, shown in Figure 3, employs sets of small and large gears mounted on the same shaft that interlock with other sets of gears to transfer power while providing torque multiplication and speed reduction (with a train value of 9.6). The structure shown couples the output gear of a microengine to a rack and pinion unit that provides linear motion with high torque.

This transmission, the microengine described previously, a pin-in-maze discriminator, and a set of out-of-plane mirrors will be combined in future work to form a complete microlock.

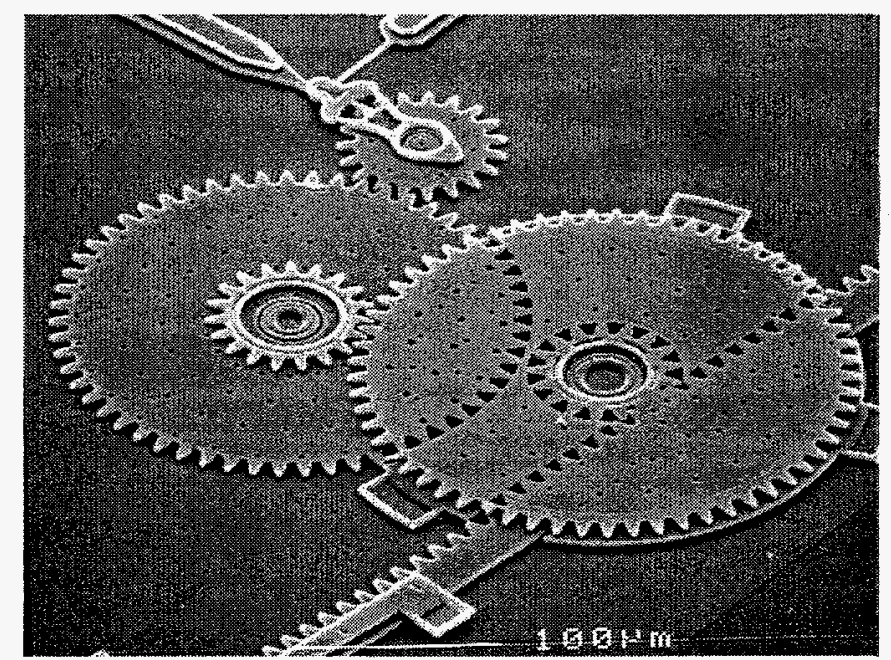

Figure 3. An electrostatic microengine output gear coupled to a double-level gear train that drives a rack and pinion slider

\subsection{Chemical-Mechanical Polishing (CMP)}

The principle technology challenge that severely limits the implementation of multiple levels of structural poly in a MEMS fabrication process is surface topography caused by the material deposition and material removal processes. As relatively thick $(\geq 2 \mu \mathrm{m})$ layers of polysilicon and oxide are deposited and etched, considerable surface topography cumulatively develops which imposes limitations in deposition, patterning, and etching of subsequent layers. Ideally, each layer of deposited material would be planarized to eliminate the process challenges imposed by cummulative surface topography. These processing challenges introduced by surface topography include photoresist step coverage, depth-of-focus of photolithography equipment, and stringer generation during dry etch. Presently, other researchers address these problems 
through careful design of structures, special photoresist processes, and the use of extra mask levels. photolithography, and materials.

Sandia has applied the relatively new process technology called, chemical-mechanical polishing or CMP, to literally planarize surface topography at specific steps of the process flow. CMP technology was originally developed as a planarization tool for the manufacturing of multi-level metal interconnects used in high-density integrated circuits ${ }^{3}$. At Sandia, we have extended the use of CMP from sub-micron integrated circuit manufacturing to the fabrication of more advanced and complex surface-micromachined micro-electromechanical systems (MEMS). CMP is a critical component of the SUMMiT process enabling planar deposition in muliple layer micromachining processes.

The SEM cross-sections illustrated in Figure 4 depicts the surface topography before (left) and after (right) CMP of a CVD TEOS film deposited on patterned polysilicon devices. This demonstrates the effectiveness of CMP for planarizing sacrificial oxide layers deposited over MEM structures.
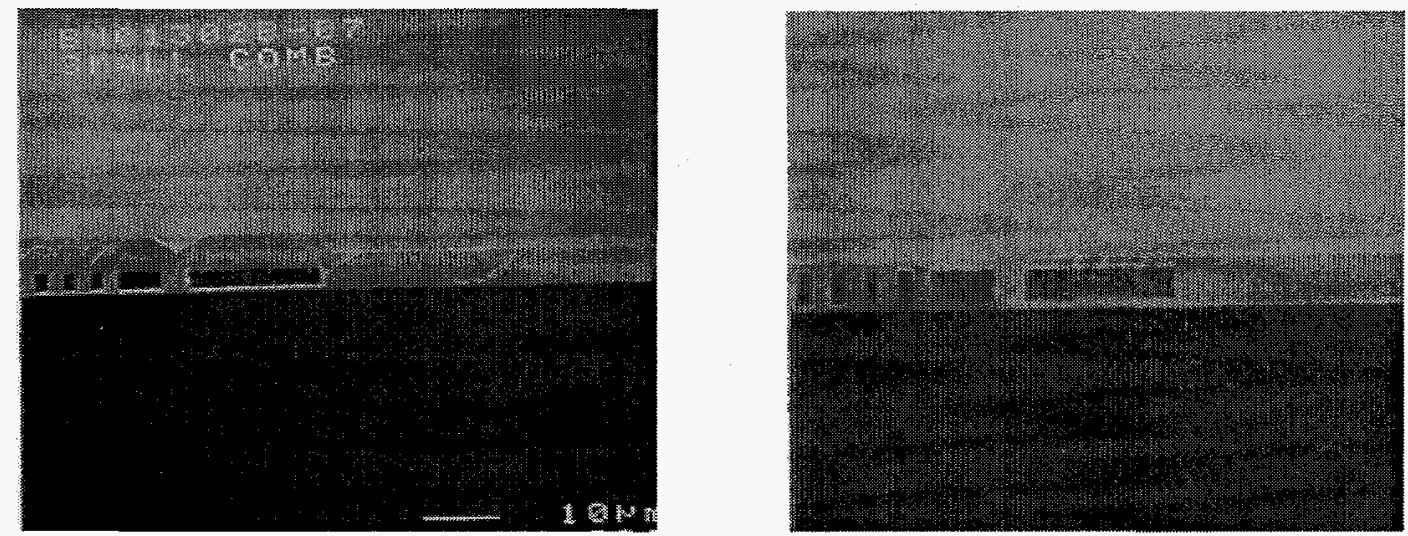

Figure 4. Cross-section of a micromachine showing the topography before (left) and after (right) CMP planarization

CMP is also being used in the fabrication of other micromechanical devices at Sandia including planar pressure sensors and integrated MEMS/CMOS devices.

\subsection{DESIGN TOOLS}

Efficient MEMS development not only requires reliable and repeatable fabrication processes, but it also requires flexible and integrated design and analysis tools. Several commercial entities have developed design tools for MEMS, each with its unique set of strengths and weaknesses. Additionally, assorted non-MEMS design tools have been applied to design and analysis of MEMS according to the abilities and needs of MEMS designers.

\subsection{AutoCAD® Mask Layout Tools}

The layer geometry (including layers of polycrystalline silicon, silicon dioxide, and silicon nitride) of each patterning step in the fabrication of MEMS devices is defined by a 2-D mask. Masks are fabricated from 2-D AutoCAD ${ }^{\circledR}$ software drawing files. AutoCAD ${ }^{\circledR}$ is a general purpose mechanical design and drafting software package that is widely used in the engineering community. Because of its widespread use, AutoCAD ${ }^{\circledR}$ has many interfaces and $3^{\text {rd }}$ party software modules that makes it use viable in a variety of MEMS design applications.

Each mask level in the SUMMiT process corresponds to one or more AutoCAD ${ }^{\circledR}$ drawing layers. Some mask levels correspond to multiple drawing layers in order to simplify the layout of mask levels. For example, Figure 5 shows a typical set of AutoCAD layers used to define the composite geometry of a structural poly layer. In this example, one layer in AutoCAD ${ }^{\circledR}$ will be used to define the main structural geometry of a layer, then a second AutoCAD ${ }^{\circledR}$ layer will be used to 
define geometry within the main structural layer to be removed (like etch release holes). The two AutoCAD ${ }^{\circledR}$ layers are then combined using an XOR (exclusive OR) operation to create a single mask layer geometry definition (Figure 6).
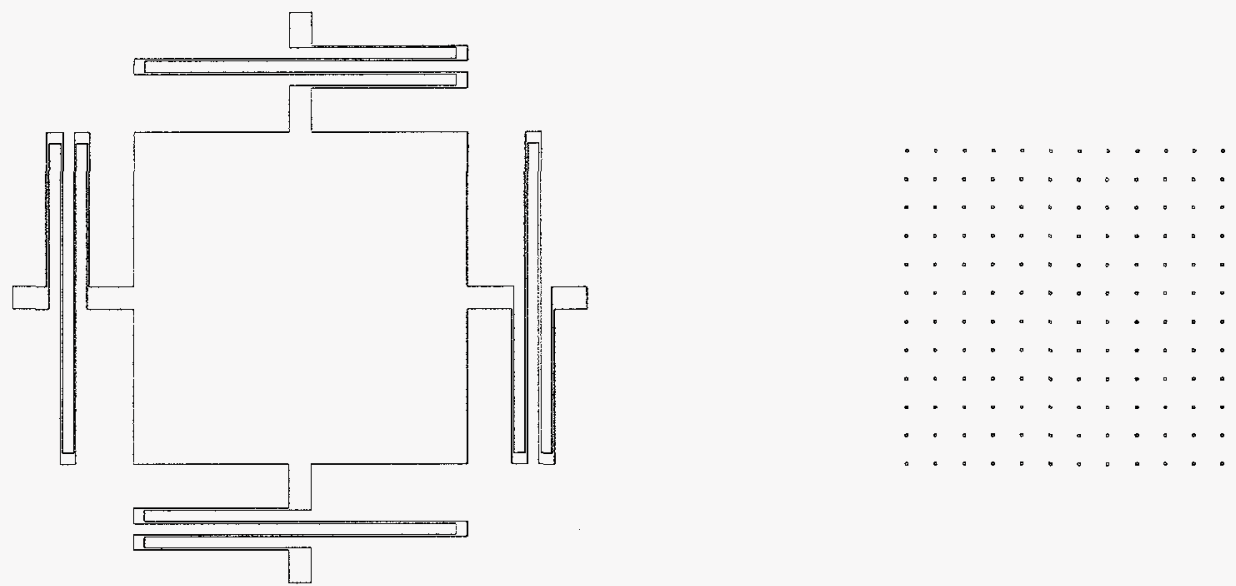

Figure 5: AutoCAD $^{\circledR}$ layer showing structural poly geometry (left) and AutoCAD ${ }^{\circledR}$ layer showing etch release holes in structural poly geometry (right)

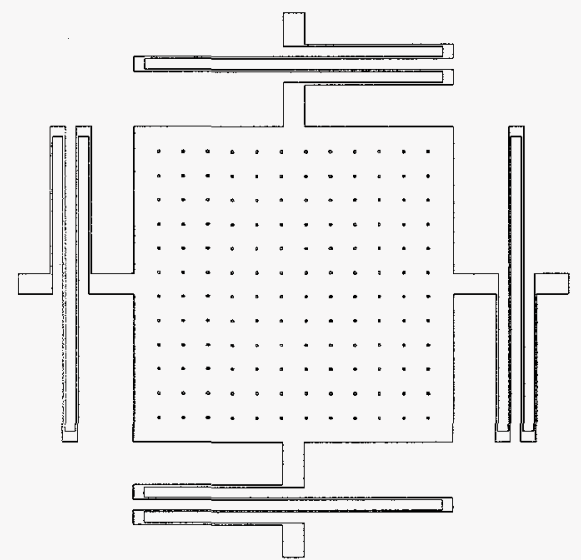

Figure 6: AutoCAD ${ }^{\circledR}$ structural poly geometry layer after $\mathrm{XOR}$ operation with etch release hole AutoCAD ${ }^{\circledR}$ layer.

Once mask levels have been defined within AutoCAD ${ }^{\circledR}$, certain types of design errors are checked with design rule checking software. The design rule checking software checks such geometric features as minimum feature resolution, minimum spacing between adjacent elements, etch release hole spacing, etc. Design rule checking helps improve MEMS device yield by flagging geometric features that will likely result in process or design problems.

\subsection{Mechanical Finite Element Analysis Software}

Certain kinds of finite element analysis software can be applied to MEMS devices as long as a good understanding of device and microdomain physics are taken into account and scaling and unit conversion is performed correctly. In the MEMS domain, effects due to Van der Waals forces, capillary and surface tension effects, and electrostatic forces can easily exceed inertial, material deflection, and friction forces which usually dominate models of macrodomain devices.

\subsubsection{ANSYS AutoFEA ${ }^{\circledR}$ 3-D Finite Element Analysis Software}

Finite element analysis software was used to verify the design of an accelerometer, shown in previous figures. The finite element software that was used is called ANSYS/AutoFEA ${ }^{\circledR} 3 \mathrm{D}$, and is compatible with AutoCAD ${ }^{\circledR}$ generated geometry. 
Results of this analysis software predicted maximum deflection at $10 \mathrm{G}$ 's of 0.15 microns (for the open loop control case) and resonance at $4 \mathrm{kHz}$ (Figure 7 and Table 1). Additionally, the design factor of safety exceeds 10 for the stress states calculated for a $10 \mathrm{G}$ acceleration event.

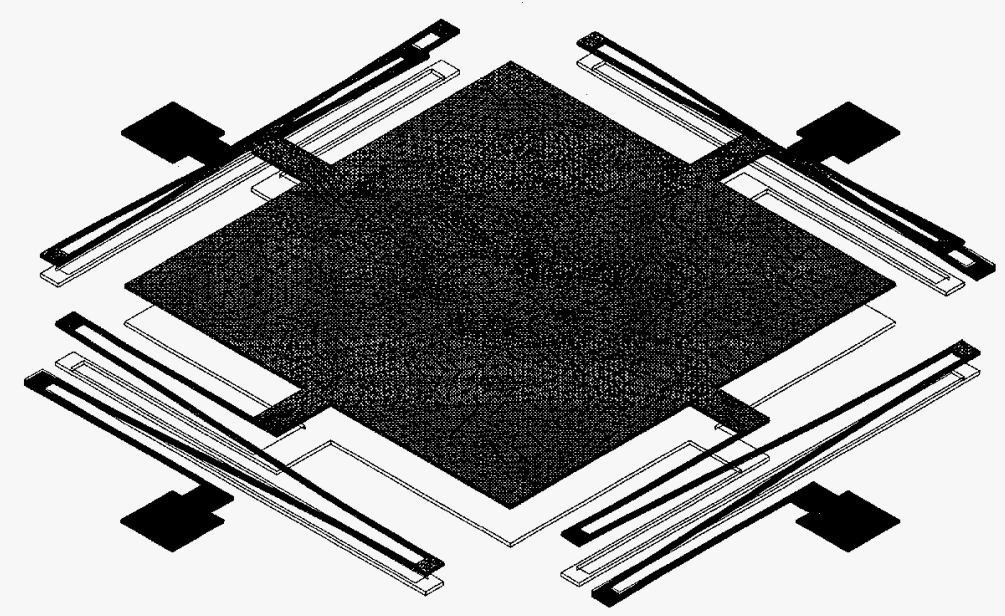

Figure 7: Low g accelerometer deflection at $10 \mathrm{G}$ 's

$$
\begin{array}{|cc|}
\hline \text { Vibration Frequencies: } & \text { - Maximum Deflection } \\
\text { - Mode 1: } 3,898 \mathrm{~Hz} & (@ 10 \mathrm{~g} \text { 's): } \\
\text { - Mode 2: } 7,008 \mathrm{~Hz} & -0.15 \text { microns } \\
\text { - Mode 3: } 7,049 \mathrm{~Hz} & - \text { Maximum Stress } \\
\text { - Mode 4: } 13,281 \mathrm{~Hz} & (@ 10 \mathrm{~g} \text { 's): } \\
\text { - Mode 5: } 13,573 \mathrm{~Hz} & -925 \mathrm{KPa} \\
\text { - Mode 6: } 19,592 \mathrm{~Hz} & \\
\hline
\end{array}
$$

Table 1: Finite element predictions of frequency modes, maximum deflection and stress of low $\mathrm{G}$ accelerometer

\subsubsection{Microcosm MEMCAD Visualization and Finite Element Analysis Software}

At Sandia, an agreement between Microcosm, Inc. and Sandia has made a MEMS design, modeling, and finite element analysis software package called MEMCAD ${ }^{\circledR}$ available to designers using the SUMMiT process. With MEMCAD ${ }^{\circledR}, a$ MEMS designer can model and analyze a MEMS design with such capabilities as the 3-D visualizer (automatic construction of a 3-D model of the MEMS device based on the composite of the 2-D mask definitions and the fabrication process description), automatic meshing of the MEMS model (designer defines boundary conditions and loads then the software automatically creates a finite element mesh of the 3-D model), solver analysis (full model analysis of characteristics such as structural mechanics, electrostatics, vibration, heat transfer, fluid flow, and coupled electro-mechanics), and simulation management (iterative analysis used to formulate the sensitivity between device performance parameters and changes in design or operating parameters). The process flow employed in the MEMCORE 3-D ${ }^{\circledR}$ visualization software is shown in Figure 8 below. 


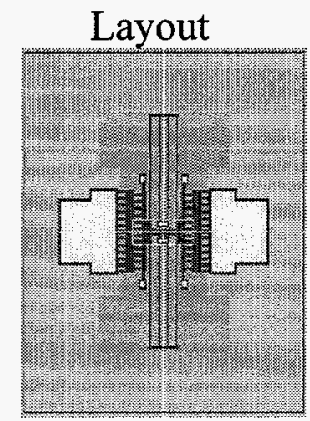

\section{Process Description}
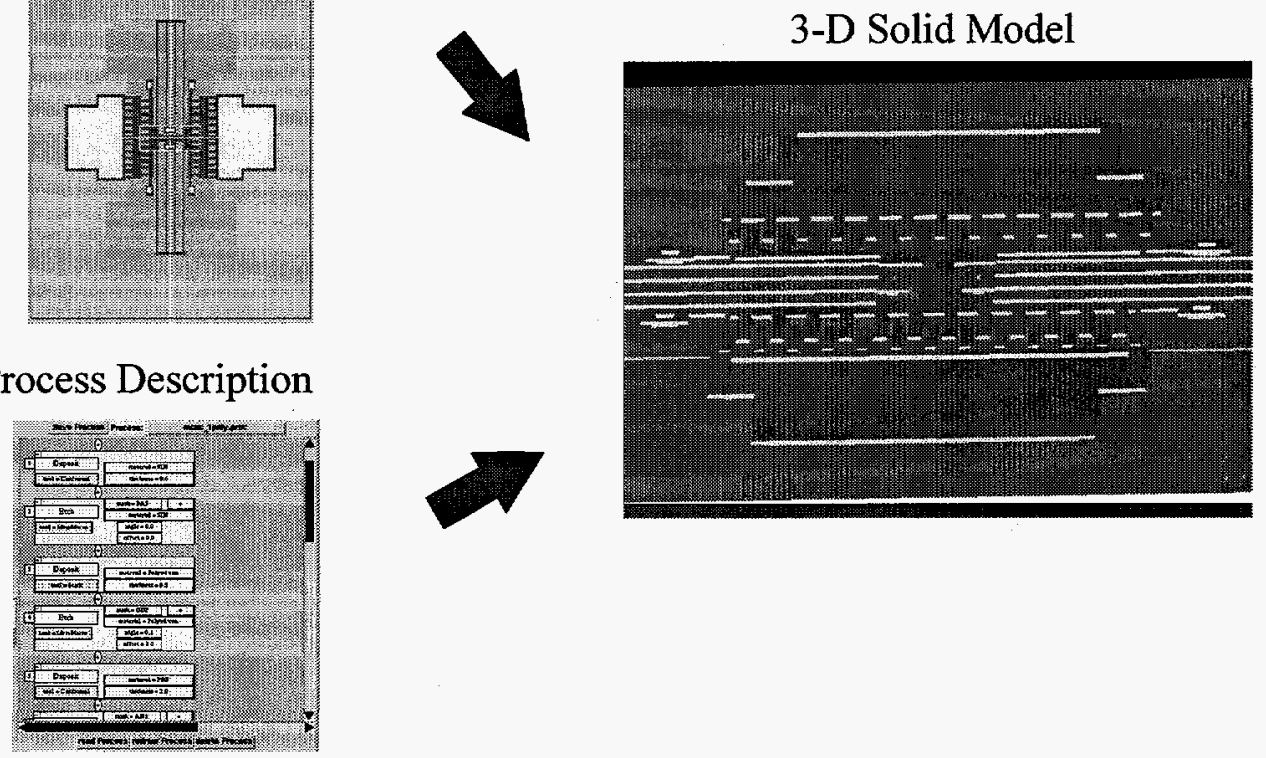

Figure 8: $\mathrm{MEMCORE}^{\circledR}$ consists of a 3D geometry engine, layout tools, and a process description editor

\subsection{Standard Mechanical Components Library}

Certain mechanical components can be used in a variety of applications, and so it makes sense to develop an infrastructure and means for creating a database of useful MEMS mechanical components that can be inserted into appropriate designs. This database infrastructure has been configured as part of the SUMMiT design process as a library of standard components. Component designs already existing in the standard components library are currently available to process users. Additional components are constantly being added to the library to expand its usefulness. Figure 9 shows the functional index menu for the standard components database.

\section{FUNCTION}

\section{HoMe}

Baticte

cLussaRY

To view components by function, select from one of the following:

\begin{tabular}{|c|c|}
\hline Function & Component Type \\
\hline Energy Storage & Springs, Capacitors \\
\hline Energy Generation & Pendulum, Coil \\
\hline Energy Transmission & $\mathrm{XY}$-linkage, Z-linkiage, Gears, Couplers \\
\hline Energy Transformers & Gear Trains, Transformers \\
\hline Actuators & $\begin{array}{l}X \text {-Comb Drive, } X \text {-Comb Drive, Steam Engines, Microlock } \\
\text { Microengines, Comtois, Stopper, } X X \text {-Actuator, Z-Actuator }\end{array}$ \\
\hline Sensors & Low G, High G, Gyros, Bolometer \\
\hline Communications & Comer Cube Ref, Modulation Mrror, Coil \\
\hline Diagnostics & Diagnostic Module Rev C \\
\hline Miscellaneous & Sandia Thanderbird \\
\hline
\end{tabular}

Figure 9: Standard components library function index 
Using the standard component library in the SUMMit process, very sophisticated micromachines (like the pop-up mirror assembly shown below) can be fabricated by coupling individual components together. In the pop-up mirror assembly shown in Figure 10, electrostatic comb drives are coupled to a drive a $50 \mu \mathrm{m}$ diameter pinion gear meshed to a 10:1 speed reduction transmission. The transmission is coupled directly to a linear rack which drives the motion of the the hinged micromirror between 0 and $90^{\circ}$. The electrostatic comb drives, pinion gear, speed reduction transmission, linear rack, and pop-up mirror are each components available to SUMMiT process users through the standard components library.

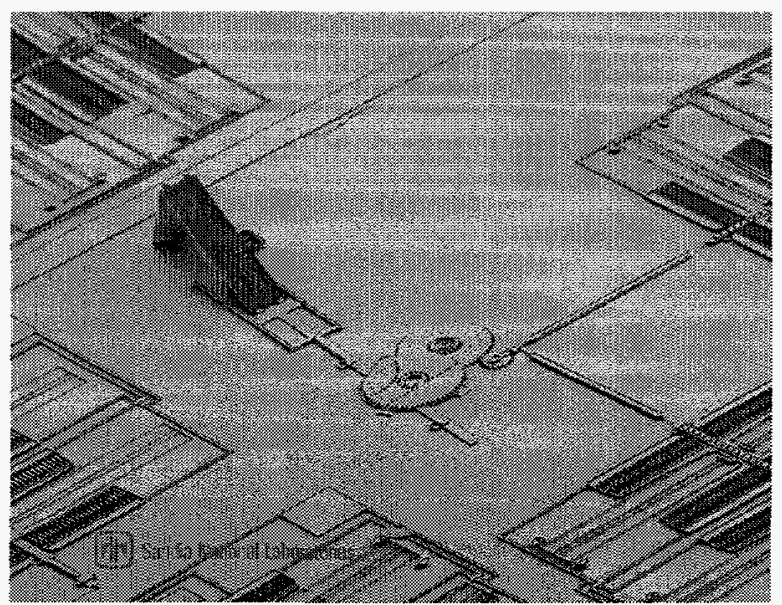

Figure 10: Pop-up mirror with rack and pinion drive system

\subsection{Design Rule Checking Software}

Design rule checking (DRC) is the process of checking for violations of design rules for the SUMMiT process. Design rules implemented include minimum feature widths, minimum feature spacing, feature overlap dimensions, etch release hole spacing, etc. First the AutoCAD ${ }^{\circledR}$ mechanical design package is used to define MEMS device geometry layout. Then the device geometry file is translated into a format that can be processed by an integrated circuit layout package (in this case IC Station) that supports DRC for integrated circuits. Special design rules are implemented in IC Station relevant to design of MEMS structures in the SUMMiT process. The DRC capability helps MEMS designers avoid design mistakes that would jeopardize proper function of their MEMS device (such as not completely separating parts that move relative to each other) or adversely impact other designs on the same wafer (such as not anchoring parts that would float free from one design and mechanically interfere with operation of other designs as shown in Figure 11).

Figure 11: Parts improperly anchored

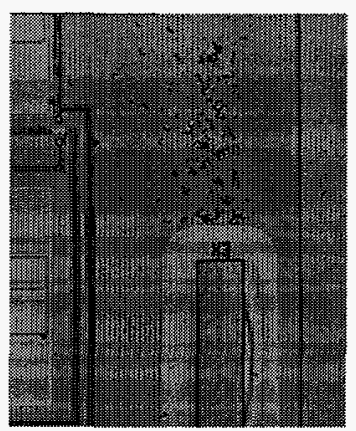

The DRC process proceeds as follows. First the designer creates an AutoCAD file defining the various mask levels of a MEMS device in the SUMMiT process. The AutoCAD file is then saved in a DXF format (AutoCAD drawing interface format). The DXF file is then translated to a GDSII (ASM3500 by Artwork Conversion) format. The GDSII format can then be translated and processed by IC Station software (Mentor Graphics IClink) where the design rule checking is performed. An error file in DXF format from the resulting ASCII DRC generated log file. Finally the DXF errors file is overlaid over the AutoCAD drawing file to show error locations. Additionally, a series of error codes are provided that 
describe the nature of the error at each error location. All the above mentioned processes are automatically initiated in the proper sequence by interacting with the DRC toolbar shown in Figure 12.

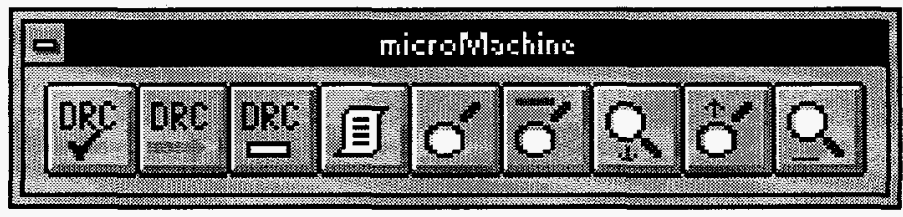

Figure 12: Design Rule Checking toolbar

The first icon (leftmost in Figure 12) initiates the DRC process and returns a results file to the AutoCAD workstation that initiated the DRC process. The other icons are used to automatically load and overlay any DRC flagged errors on the AutoCAD ${ }^{\circledR}$ file checked for the user to visually note error locations. By clicking on the overlaying errors markers, information regarding the nature of the error is automatically displayed.

\subsection{ACCELEROMETER DESIGN EXAMPLE}

Accelerometers are important sensors in a variety of applications ranging from air bag actuation and anti-skid braking to navigation and flight control. An accelerometer was designed and will be fabricated using the four-level polycrystalline silicon process developed at Sandia. This accelerometer was designed to measure accelerations between \pm 25 G's. Design of was accomplished using many of the design tools described in this paper. Various intermediate design steps are illustrated in earlier figures and tables, specifically Figures 5-7 and Table 1.

\subsection{Accelerometer suspension design}

The accelerometer consists of a plate or proof mass suspended by four folded springs. Above and below the suspended proof mass are an upper and lower electrode, respectively. Each electrode acts as one electrode in a parallel plate capacitor, where the suspended proof mass, which at equilibrium is centered between the upper and lower electrodes, acts as the second parallel plate for both the upper and lower electrodes. Accelerations cause the suspended proof mass to be deflected towards the upper or lower electrode. This changes the capacitance between the upper electrode and the proof mass as well as the capacitance between the lower electrode and the proof mass. This change in capacitance is detected and a voltage is applied to the electrode that is sensing the proof mass moving away from it. This results in an electrostatic attraction force between the suspended plate mass and the electrode which keeps the proof mass centered between the upper and lower electrode. The voltage (or number of discrete voltage pulses) required to keep the proof mass centered is a measure of acceleration.

The spring suspension system as well as electrostatic electrodes can be seen in this AutoCAD ${ }^{\circledR}$ rendering of the accelerometer (Figure 13). Mechanical stops were also implemented at each corner and the center of the capacitive plate sensor to restrict lateral and vertical movement during shock or other high acceleration events.

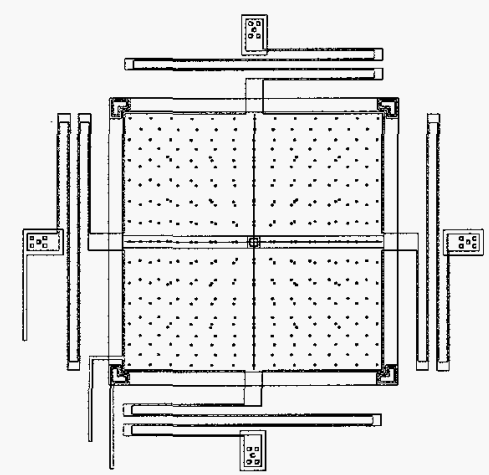

Figure 13: AutoCAD ${ }^{\circledR}$ rendering of an accelerometer design 
Additionally, the accelerometer mechanical structure was designed to be controlled using a $\Sigma \Delta$ control system similar to those designed by Lemkin, et. al. at the University of California at Berkeley ${ }^{8}$.

\subsection{Damping}

Damping was determined by simultaneously applying two different models of squeeze film damping, each of which models some but not all of the applicable characteristics of the suspended mass prototype. (Squeeze-film damping can be defined as the viscous loss of energy due to pumping a viscous fluid out from or into the volume between two moving surfaces.)

The first model ${ }^{9}$ is applicable to squeeze-film damping between two parallel disks without perforations that are separated by several $\mu \mathrm{m}$. In this model, viscous damping occurs due to the movement of fluid around the outside edges of the plates. The damping resistance, $\mathrm{R}_{\mathrm{film}}$, is characterized by the following equation:

$$
\mathrm{R}_{\text {film }}=3 \mu \mathrm{S}^{2} / 2 \pi \delta^{3} \quad(\mathrm{~N}-\mathrm{s} / \mathrm{m})
$$

where $\mu$ is the fluid viscosity $\left(18 \times 10^{-6} \mathrm{~kg} / \mathrm{m}\right.$-s for air at $\left.20^{\circ} \mathrm{C}\right), \mathrm{S}$ the plate area overlap, and $\delta$ the average plate spacing. The second model $^{9}$ is applicable to squeeze-film damping when one plate is perforated. In this model, viscous damping occurs due to the flow of fluid through the perforations. The damping resistance, $R_{\text {perf }}$, is characterized by the following equation:

$$
\mathrm{R}_{\text {perf }}=12 \mu \mathrm{G}(\mathrm{A}) \mathrm{S}^{2} / \mathrm{N} \pi \delta^{3} \quad(\mathrm{~N}-\mathrm{s} / \mathrm{m})
$$

where $\mathrm{A}$ is the fraction of open area in the plate, and $\mathrm{N}$ is the total number of holes in the perforated plate. The function $G(A)$ is described in equation (3).

$$
\mathrm{G}(\mathrm{A})=\left[\mathrm{A} / 2-\mathrm{A}^{2} / 8-(\ln \mathrm{A}) / 4-3 / 8\right]
$$

Both models were applied to the design of the suspended mass accelerometer by modeling each of their respective damping contributions and combining them as parallel elements. Additional models can be applied to predict high frequency damping (frequencies greater than $10 \mathrm{kHz}$ ).

The suspended proof mass is perforated by $144,2 \mu \mathrm{m} \times 2 \mu \mathrm{m}$ etch-release holes (see Figures 5 and 6 ). The number and spacing of the etch-release holes (necessary for proper fabrication of the sensor element) results in a very low damping ratio (very high $\mathrm{Q}$ ). The calculated natural frequency of the sensor is $4,070 \mathrm{~Hz}$ which is very close to the resonant frequency of $3,898 \mathrm{~Hz}$ predicted using the finite element analysis of Table 1.

\subsection{SAMPLE SHORT COURSE}

A short course is taught approximately every other month at Sandia's MEMS design facility in Albuquerque, New Mexico. The MEMS Short Course introduces the SUMMiT process and design information relevant to micromachine design. The following topics are covered during the course: IC fabrication processes used for MEMS, overview of MEMS technologies, MEMS sensors, MEMS actuators, SUMMiT process (including process flow and materials), SUMMiT process design rules, mechanical design of MEMS devices, MEMS analysis tools and models, MEMS performance analysis, and reliability analysis.

Additionally, hands-on training in design and CAD layout using the AutoCAD ${ }^{\circledR}$ design tools and hands-on performance characterization training is provided during the course for those designing MEMS modules using the SAMPLE system.

\subsection{SUMMARY}

Sandia's four-level polysilicon SUMMiT process enables the design and fabrication of intricate mechanisms such as microengines, microtransmissions, and microlocks. Design tools and infrastructure have been developed to support the 
fabrication of these sophisticated devices. This process has been used successfully by both internal and external MEMS designers in a wide variety of device applications. Using the SUMMiT design tools and process, it is possible to design and fabricate complex MEMS devices that work after only one design cycle ${ }^{10}$.

\section{ACKNOWLEDGMENTS}

The authors wish to express their sincere appreciation to the engineers and technicians who have developed and implemented the processes used in fabricating the micromachines described in this paper. Without the outstanding assistance of these dedicated professionals, the work described above could not have been accomplished.

\section{REFERENCES}

1. S. Marshall, T. Studt, R. Cassidy, "Micromachine sales to grow 50\% a year", Micromachine Devices, Vol. 1 , No. 1, September 1996.

2. System Planning Corporation, "MicroElectroMechanical Systems (MEMS) - An SPC Market Study", System Planning Corporation, 1994.

3. J. Smith, "Micromachined Sensor and Actuator Research at Sandia's Microelectronics Development Laboratory", Invited Presentation, Proc. Sensors Expo Anaheim '96, pp. 119-123, April, 1996.

4. J. Sniegowski and E. Garcia, "Microfabricated actuators and their applications to optics," Proceedings of SPIE Photonics West 95 , SPIE, 1995.

5. J. Sniegowski and E. Garcia, "Surface-micromachined geartrains driven by an on-chip electrostatic microengine," IEEE Electron Device Letters, vol. 17, no. 7, p. 366, 1996.

6. J. Sniegowski, S. Miller, G. LaVigne, M. Rodgers, and P. McWhorter, "Monolithic geared-mechanisms driven by a polysilicon surface-micromachined on-chip electrostatic microengine," Proc. Solid-State Sensor and Actuator Workshop, pp. 178-182, 1996.

7. R. Nasby, J. Sniegowski, J. Smith, S. Montague, C. Barron, W. Eaton, P. McWhorter, D. Hetherington, C. Apblett, and J. Fleming, "Application of chemical-mechanical polishing to planarization of surface-micromachined devices," Proc. Solid-State Sensor and Actuator Workshop, pp. 48-53, 1996.

8. M. A. Lemkin, M. A. Ortiz, N. Wongkomet, B. E. Boser, J. Smith, "A 3-Axis Surface Micromachined $\Sigma \Delta$ Accelerometer", IEEE International Solid-State Circuits Conference, pp. 202-203, 1997.

9. T. B. Gabrielson, "Mechanical-Thermal Noise in Micromachined Acoustic and Vibration Sensors", IEEE Transactions on Electron Devices, Vol. 40, No. 5, May, 1993.

10. J. H. Comtois, M. Adrian Michalicek, Carole Craig Barron, "Characterization of Electrothermal Actuators and Arrays Fabricated in a Four-Level, Planarized Surface-Micromachined Polycrystalline Silicon Process", International Conference on Solid-State Sensors and Actuators (Transducers '97), pp. 769-772, 1997.

\section{DISCLAIMER}

This report was prepared as an account of work sponsored by an agency of the United States Government. Neither the United States Government nor any agency thereof, nor any of their employees, makes any warranty, express or implied, or assumes any legal liability or responsibility for the accuracy, completeness, or usefulness of any information, apparatus, product, or process disclosed, or represents that its use would not infringe privately owned rights. Reference herein to any specific commercial product, process, or service by trade name, trademark, manufacturer, or otherwise does not necessarily constitute or imply its endorsement, recommendation, or favoring by the United States Government or any agency thereof. The views and opinions of authors expressed herein do not necessarily state or reflect those of the United States Government or any agency thereof. 


\section{DISCLAMMER}

Portions of this document may be illegible in electronic image products. Images are produced from the best available original document. 